\title{
Evaluation of a strategy for identifying nodulation competitiveness genes in Rhizobium leguminosarum biovar phaseoli
}

\author{
Gwyn A. Beattie $\dagger$ and Jo Handelsman* \\ Department of Plant Pathology and Center for the Study of Nitrogen Fixation, University of Wisconsin, \\ 1630 Linden Drive, Madison, WI 53706, USA
}

(Received 13 July 1992; revised 28 October 1992; accepted 5 November 1992)

\begin{abstract}
Rhizobium leguminosarum biovar phaseoli strain KIM5s is consistently much more competitive than strain CE3 in nodulation of beans (Phaseolus vulgaris $\mathrm{L}$.) in the laboratory and in the field. To identify genes that contribute to the competitiveness of KIM5s, we transferred a cosmid library containing KIM5s DNA into CE3 and applied the transconjugants to bean plants to allow the plants to enrich for those with enhanced nodulation competitiveness. The nodule isolates were then applied to plants for further enrichment. Of 75 isolates from nodules sampled after the two enrichments, 9 were more competitive than CE3. For example, when outnumbered in the inocula 40 -fold by a reference strain, these nine strains typically occupied $15-40 \%$ of the nodules compared with 0-3\% for CE3. However, when these strains were cured of the cosmids, they remained highly competitive, demonstrating that the enhanced competitiveness of the strains was not associated with the cosmids. We found no evidence for cosmid insertion into the chromosome or for cosmid-induced genetic changes in these cured strains. We found some evidence suggesting that their altered competitiveness was due to spontaneous genetic changes that did not involve the cosmids. Although these highly competitive variants remain genetically uncharacterized, they may provide insight into bacterial traits that contribute to, or detract from, successful nodulation competitiveness.
\end{abstract}

\section{Introduction}

The success of a micro-organism living among other micro-organisms depends on genes that contribute to its survival or successful competitiveness. By identifying these genes and the traits they confer, we will begin to understand the survival strategies of micro-organisms in specific environments. Plant-associated bacteria provide interesting models for studying the determinants of ecological fitness, since the plant may provide a highly selective habitat for the bacteria.

The approach most commonly taken to identify determinants of ecological fitness is to test whether specific phenotypes identified in culture affect survival or competition. For example, in studies of the colonization fitness of plant-associated bacteria, Haefele \& Lindow (1987) tested mutants for a role of motility in epiphytic colonization by Pseudomonas syringae, and Anderson et

\footnotetext{
*Author for correspondence. Tel. (608) 263 8783; fax (608) 263 2626; email joh@plantpath.wisc.edu.

$\dagger$ Present address: Department of Plant Pathology, University of California, 147 Hilgard Hall, Berkeley, CA 94720, USA.
}

al. (1988) tested for a role in agglutination by a plant glycoprotein in root colonization by $P$. putida. Although this predictive approach has led to the identification of characteristics involved in bacterial behaviour in natural habitats, other approaches may be useful to understand these complex phenotypes. By exploiting the selective pressures exerted by specific habitats and applying modern molecular techniques, we should be able to identify genes that affect bacterial behaviour in a specific environment and then identify their functions. The attraction of this shotgun approach is that it has the power to extend beyond the predictive abilities of the researchers.

Bacteria of the genus Rhizobium are ideal candidates for studying competitive behaviour, because the root nodules that they induce in symbiotic association with legumes usually contain pure cultures of the successful competitor. Root nodules therefore could provide a source of highly competitive genetic variants enriched from the rhizosphere population.

Through mutant analysis, phenotypic alterations identified in culture have been correlated with changes in competitiveness. Such studies have shown that competitiveness is affected by motility and chemotaxis (Ames 
\& Bergman, 1981; Caetano-Anollés et al., 1988; Liu et al., 1989; Mellor et al., 1987; Zdor \& Pueppke, 1991), cell surface polysaccharides (Araujo \& Handelsman, 1990; Bhagwat \& Keister, 1990; Handelsman et al., 1984; Milner et al., 1992; Trinick \& Hadobas, 1989; Ugalde et al., 1986; Zdor \& Pueppke, 1991; Lagares et al., 1992), bacteriocin production (Triplett \& Barta, 1987), succinate-sensitivity (Urban, 1988), and rate of nodule induction (Hahn \& Hennecke, 1988). Such studies have also demonstrated that the ability to fix nitrogen (Amarger, 1981; Hahn \& Struder, 1986; Sanjuan \& Olivares, $1991 b$ ) and to metabolize particular aromatic compounds (Rynne et al., 1988) does not affect competitiveness under the conditions tested.

Although successful competitiveness is likely to be conferred by multiple, possibly interacting, mechanisms that are controlled by many genes, the above studies demonstrate that altering a single gene can result in a detectable change in competitiveness. A strategy for identifying such genes, which is complementary to the predictive approach, is to identify randomly generated genetic changes that either contribute to or detract from competitiveness and then determine the cellular functions of the genes involved. An analogous approach was used to identify and functionally characterize nod genes in Rhizobium spp. (Long et al., 1982; Kondorosi, 1989), and vir (Douglas et al., 1985; O'Connell \& Handelsman, 1989), avr (Ronald \& Staskawicz, 1988; Swanson et al., 1988), and hrp (Lindgren et al., 1986; Grimm \& Panopoulos, 1989) genes in plant-pathogenic bacteria. In the only previous study to apply this shotgun strategy to nodulation competitiveness, McLoughlin et al. (1987) generated 600 random Tn 5 mutants of $R$. fredii and identified four that were reduced in competitiveness. Unfortunately, they were unable to identify the physiological function of the gene(s) involved. An alternative to generating random mutants would be to transfer genes from one strain to another and screen for altered competitiveness. Although this requires that all of the genes involved in a single mechanism of competitiveness be clustered and that these genes be functionally dominant in the recipient, success with this approach directly provides clones of the gene(s) of interest.

We define nodulation competitiveness as the relationship between the ratio of strains in the inoculum and the ratio of nodules occupied by each strain. In a previous evaluation of the relative competitiveness of two $R$. leguminosarum bv. phaseoli strains, KIM5s and CE3, we showed that KIM5s is consistently much more competitive than CE3 in nodulating beans in the laboratory and in the field (Beattie et al., 1989). This consistency is critical for a genetic study of nodulation competitiveness, because it facilitates identifying genetically altered strains whose competitiveness deviates from that of the parent strain and may make it possible to identify genes in the laboratory that are also important for competitiveness in the field. In this paper, we report our attempts to transfer genes that influence nodulation competitiveness from KIM5s into CE3.

\section{Methods}

Bacterial strains and plasmids. These are shown in Table 1. Antibiotics, when needed, were added to the media at the following concentrations: spectinomycin (Sp), streptomycin (Sm), and kanamycin, $200 \mu \mathrm{g} \mathrm{ml}^{-1}$ vancomycin, $5 \mu \mathrm{g} \mathrm{ml}^{-1}$ and tetracycline (Tc), $20 \mu \mathrm{g} \mathrm{ml}^{-1}$.

Construction of genomic libraries of KIM5s. Standard DNA manipulations such as isolation and restriction digestion of DNA and agarose gel electrophoresis were performed as described by Ausubel $e t$ al. (1987). We constructed genomic libraries of KIM5s by partially digesting genomic DNA with Sau3A, size-fractionating it on a $10-40 \%$ linear sucrose gradient, and cloning fragments in the range $20-30 \mathrm{~kb}$ into the cosmid vectors pLAFR3 (Staskawicz et al., 1987) and pLA2917 (Allen \& Hanson, 1985). Clones were stored individually in $15 \%(\mathrm{v} / \mathrm{v})$ glycerol at $-80{ }^{\circ} \mathrm{C}$. We isolated cosmids by the method of Birnboim (1983) and determined the average insert size in each library by examining BamHI restriction patterns of cosmid DNA.

We transferred the libraries into CE3 by the method of Triplett (1988). Each mating mixture contained 48 cosmid clones in Escherichia coli strain DH1, the recipient CE3, and E. coli strain DH $\alpha \propto($ pRK2013). CE3 transconjugants were selected on BSM agar (Bergersen, 1961) containing Sm and Tc.

Plant growth conditions and preparation of inocula. Seeds of all Phaseolus vulgaris L. (bean) cultivars were the gift of K. Kmiecik, Department of Horticulture, University of Wisconsin-Madison, USA. Seeds were surface-sterilized immediately before planting by rinsing them for $30 \mathrm{~s}$ in ethanol, $3 \mathrm{~min}$ in $1 \%(\mathrm{w} / \mathrm{v})$ sodium hypochlorite, and $3 \mathrm{~min}$ in sterile water. Unless otherwise indicated, seeds of the common black bean cultivar WBR22-34 were planted in sterilized sand and vermiculite (1:1 by volume) in glass tubes (Araujo et al., 1986) and grown in a growth chamber as described previously (Beattie et al., 1989).

Inocula were prepared by growing each strain to early stationary phase in yeast extract/mannitol (YM) broth (Wacek \& Brill, 1976) at $28^{\circ} \mathrm{C}$. An inoculum $\left(1 \mathrm{ml}\right.$ ) containing $10^{7}-10^{8}$ cells was applied directly to each seed before covering. Three weeks after planting, nodules were removed, surface-sterilized, and nodule bacteria were plated as described previously (Beattie \& Handelsman, 1989).

Cosmid stability in culture and during nodulation. We examined the stability of the cosmids in five independent transconjugants from each library. We grew two replicates of each transconjugant for approximately 10 generations in $\mathrm{YM}$ broth at $28^{\circ} \mathrm{C}$ and enumerated the bacteria on YM agar with and without Tc. We calculated the mean percentage of Tc-resistant cells in the ten cultures that represented each library. To evaluate cosmid stability in planta, we applied each transconjugant to two seeds of cultivar Puebla 152, crushed five nodules from each plant, and enumerated the bacteria from each nodule on YM agar with and without Tc. We calculated the mean percentage of $\mathrm{Tc}$-resistant cells in the 50 nodules that represented each gene library.

Enrichment for transconjugants with enhanced competitiveness. We used the host plant to enrich for highly competitive strains from a mixture of strains. To evaluate the selective power of the plant with strains KIM5s and CE3, we applied a 1:50 mixture of KIM5s and CE3 
Table 1. Bacterial strains and plasmids used in this study

\begin{tabular}{|c|c|c|}
\hline Designation & Relevant characteristics* & Source or reference \\
\hline \multicolumn{3}{|l|}{$\begin{array}{l}\text { Rhizobium } \\
\text { leguminosarum } \\
\text { bv. phaseoli }\end{array}$} \\
\hline KIM5s & Spontaneous $\mathrm{Sp}^{\mathrm{r}}$ derivative of KIM5, $\mathrm{Cmp}^{++}$ & Beattie et al. (1989) \\
\hline CE3 & Spontaneous $\mathrm{Sm}^{\mathrm{r}}$ derivative of $\mathrm{CFN} 42$ & Noel et al. (1984) \\
\hline CE3013 & $\mathrm{CE} 3:: \mathrm{Tn} 5, \mathrm{Sm}^{\mathrm{r}}, \mathrm{Km}^{\mathrm{r}}, \mathrm{Cmp}^{\circ}$ & $\begin{array}{l}\text { R. S. Araujo \& } \\
\text { J. Handelsman, } \\
\text { unpublished data }\end{array}$ \\
\hline CE3(pOWR1) & $\begin{array}{l}\text { CE3 transconjugant isolated after two } \\
\text { cycles of plant nodulation, } \operatorname{Cos}^{+} \mathrm{Cmp}^{++}\end{array}$ & This study \\
\hline CE3(pOWR2) & Same as CE3(pOWR1), $\operatorname{Cos}^{+} \mathrm{Cmp}^{++}$ & This study \\
\hline CE3(pOWR14) & Same as CE3(pOWR1), $\mathrm{Cos}^{+} \mathrm{Cmp}^{++}$ & This study \\
\hline CE3(pOWR15) & Same as CE3(pOWR1), $\mathrm{Cos}^{+} \mathrm{Cmp}^{++}$ & This study \\
\hline CE3(pOWR52) & Same as CE3(pOWRl), $\operatorname{Cos}^{+} \mathrm{Cmp}^{++}$ & This study \\
\hline CE3(pOWR58) & Same as CE3(pOWR1), $\mathrm{Cos}^{+} \mathrm{Cmp}^{++}$ & This study \\
\hline CE3(pOWR71) & Same as CE3(pOWR1), $\mathrm{Cos}^{+} \mathrm{Cmp}^{++}$ & This study \\
\hline CE3(pOWR73) & Same as CE3(pOWR1), $\operatorname{Cos}^{+} \mathrm{Cmp}^{++}$ & This study \\
\hline CE3(pOWR75) & Same as CE3(pOWR1), $\operatorname{Cos}^{+} \mathrm{Cmp}^{++}$ & This study \\
\hline CE3(pOWR3) & Same as CE3(pOWR1), $\operatorname{Cos}^{+} \mathrm{Cmp}^{\circ}$ & This study \\
\hline CE3(c\#) & CE3(pOWR\#) cured of the cosmid pOWR\# & This study \\
\hline $\mathrm{CE3}^{\prime}(\mathrm{pOWR} \#)$ & $\begin{array}{l}\text { CE3 containing the pOWR\# cosmids isolated from } \\
\text { transconjugants after two cycles of plant nodulation }\end{array}$ & This study \\
\hline \multicolumn{3}{|l|}{ Plasmids } \\
\hline pLAFR3 & Broad host range cosmid vector, $\mathrm{Tc}^{\mathrm{r}}$ & Staskawicz et al. (1987) \\
\hline pLA2917 & Broad host range cosmid vector, $\mathrm{Tc}^{\mathrm{r}}$ & Allen \& Hanson (1985) \\
\hline pRK2013 & Conjugation helper plasmid, $\mathrm{Km}^{\mathrm{r}}$ & Figurski \& Helinski (1979) \\
\hline pOWR\# & $\begin{array}{l}\text { pLAFR } 3 \text { or pLA } 2917 \text { containing a } 15 \text { to } \\
30 \mathrm{~kb} \text { insert of KIM5s genomic DNA }\end{array}$ & This study \\
\hline
\end{tabular}

* Sp, spectinomycin; Sm, streptomycin; Km, kanamycin; Tc, tetracycline; ${ }^{\mathrm{r}}$, resistant; $\operatorname{Cos}^{+}$, contains a cosmid; $\mathrm{Cmp}^{++}$, more competitive than $\mathrm{CE} 3 ; \mathrm{Cmp}^{\circ}$, similar to CE3 in competitiveness; \# indicates the number assigned to the cosmid.

to five seeds, combined all of the nodules from the plants (approximately 40 nodules per plant), and counted bacteria in the crushed nodule suspension by plate dilution on YM agar containing either $\mathrm{Sm}$ or Sp. The suspension was applied to five more seeds, and the procedure was repeated.

To enrich for transconjugants with enhanced competitiveness, we applied pools of transconjugants, each containing 48 independent cosmids, to plants. Approximately $10^{7}$ cells of each pool were applied to each of five seeds. All of the nodules from the five plants were combined (approximately 40 nodules per plant), surface-sterilized, and crushed, and the bacteria were grown on YM agar containing Tc. The bacteria from plants representing a pool of cosmids were resuspended in water and $10^{7}$ cells were applied to a seed. For each pool of cosmids, one nodule isolate was selected for evaluation in a competitiveness assay.

Competitiveness assay. For nodulation competitiveness measurements, we prepared the inocula by diluting cultures of a test strain and a reference strain to the same optical density $\left(\mathrm{OD}_{600}=0 \cdot 1-0 \cdot 3\right)$ and mixing them in various ratios. We calculated the actual inoculum ratios by dilution plating each culture on selective media. Each inoculum mixture was applied to six seeds, and isolates from six nodules, selected from the crown region of each plant, were identified by their resistance to antibiotics (Beattie \& Handelsman, 1989). We determined the proportion of nodules occupied by each strain singly and by both strains.

Strain construction. We isolated cosmid DNA from transconjugants by a modified boiling method (Holmes \& Quigley, 1981). The cosmids were transformed into $E$. coli strain $\mathrm{DH} 5 \alpha$ and transferred into a stock culture of CE3 by conjugation. CE3 was subjected to a mock mating procedure by the protocol described previously with a mixture of CE3 and $E$. coli strain DH5 $\alpha$. To cure the transconjugants of cosmids, they were grown for 10 generations in YM broth and plated on YM agar. After replica plating on YM agar with and without Tc, Tc-sensitive colonies were chosen. Cosmid acquisition and loss were evaluated by Tc sensitivity and plasmid isolation followed by visualization on agarose gels (Ausubel et al., 1987).

Physiological characterization of strains. The growth rate of each strain was measured in YM broth by plate dilution on a non-selective YM medium and by measuring $\mathrm{OD}_{600}$ at selected intervals. The cultures were grown in batch culture at $28{ }^{\circ} \mathrm{C}$ with vigorous shaking.

The nodulation efficiency of the strains (Caetano-Anollés et al., 1988) was evaluated by applying serial dilutions of a culture of each strain to each of three seeds and counting the nodules that were present after three weeks. Acetylene reduction was measured according to Somasegaran \& Hoben (1985).

\section{Results}

\section{Construction of genomic libraries of KIM5s}

Since cosmids are often lost from rhizobia during nodulation (Gray et al., 1990; Haugland et al., 1984; Kahn \& Timblin, 1984; Lambert et al., 1987; Long et al., 




Fig. 1. Relationship between target size, enrichment power, and the expected frequency of isolates containing the target DNA after the plant enrichments. Target is the DNA region required for enhanced competitiveness; $10^{n}$ is the enrichment power, i.e. the magnitude of the increased representation of a strain in the mixture of bacterial isolates selected after two plant passages compared with its representation in the original inoculum mixture. Calculations are based on an average insert size of $25 \mathrm{~kb}$ and a genome size of $6500 \mathrm{~kb}$.

1982), we constructed libraries in two cosmid vectors to increase the probability of producing cosmids that would be consistently recoverable from nodules. Libraries consisted of 1300 clones derived from pLAFR 3 and 2700 clones derived from pLA2917. The average insert sizes were $26 \cdot 6 \pm 1 \cdot 1 \mathrm{~kb}$ (mean \pm SEM, $n=24$ ) and $25 \cdot 2 \pm 1 \cdot 3 \mathrm{~kb}$ $(n=24)$ for the pLAFR3 and pLA2917 libraries, respectively.

\section{Cosmid stability in culture and during nodulation}

Maintenance of the cosmids was inferred by maintenance of tetracycline resistance $\left(\mathrm{Tc}^{\mathrm{r}}\right)$. After 10 generations in culture, the percentages of cells that contained either pLAFR3- or pLA2917-derived cosmids were $69 \pm 15 \%$ $(n=10)$ and $78 \pm 6 \%(n=10)$, respectively. In nodules, the percentages were $49 \pm 8 \%(n=50)$ and $60 \pm 4 \%$ $(n=50)$, respectively. Although the stability of pLAFR3-derived cosmids was more variable than that of pLA2917-derived cosmids, cosmids from either library were present in at least some of the bacteria isolated from any given nodule. Both libraries were therefore transferred into CE3 and screened for cosmids that confer enhanced competitiveness.

Relationship between target size, enrichment power, and the expected frequency of isolates containing the target DNA

The proportion of isolates that will contain cosmids conferring enhanced competitiveness after the plant

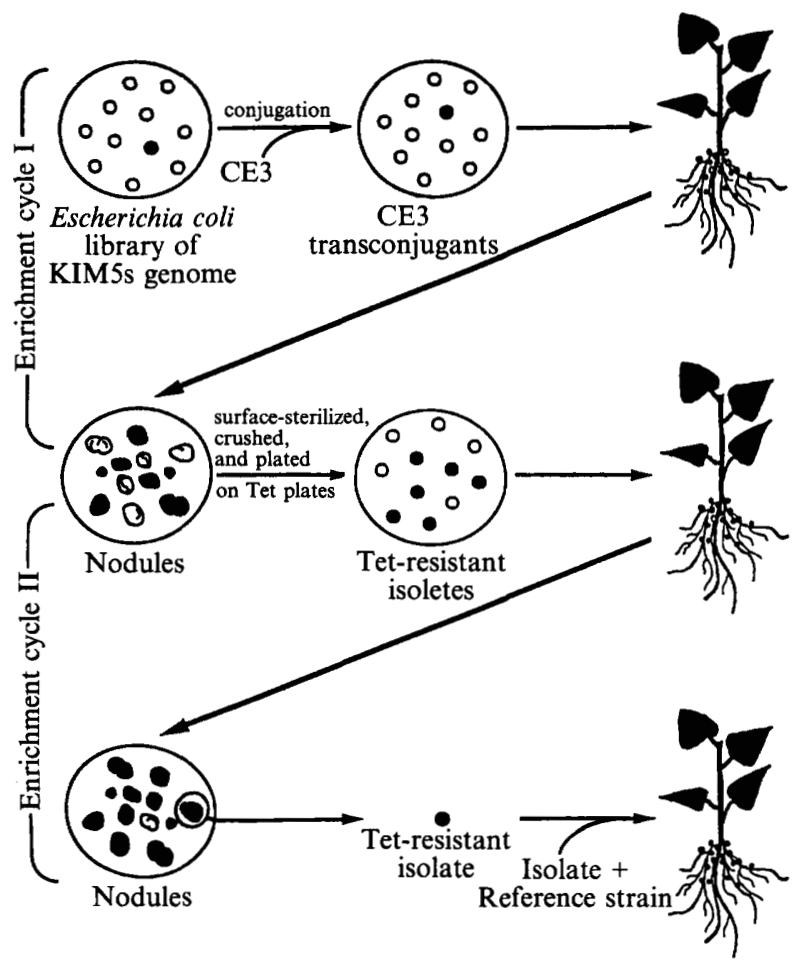

Fig. 2. Strategy for enriching for highly competitive CE3 transconjugants.

enrichments depends on two primary factors, the size of the required target DNA region and the enrichment power. The enrichment power will depend on the extent to which the target DNA enhances the competitiveness of the recipient. Assuming a completely random library, the proportion $(P)$ of cosmids containing the target DNA is related to the size of the target DNA $(T)$ as follows: $P=(1-T / I)(I / G)$, where $I$ is the average insert size in the library and $G$ is the size of the genome from which the library was derived (Clarke \& Carbon, 1976). Based on an average insert size of $25 \mathrm{~kb}$ in the KIM5s libraries and a genome size of KIM5s similar to that reported for $R$. meliloti, $6500 \mathrm{~kb}$ (Sobral et al., 1991), the predicted percentage of isolates containing the target DNA after the plant enrichments increases dramatically as the enrichment power increases and/or as the size of the target DNA decreases (Fig. 1). Based on this relationship, if $n$ isolates are selected after the enrichments, the probability that at least one will contain the target DNA is $1-(1-p)^{n}$ where $p$ is the predicted proportion of isolates containing the target at a given target size and enrichment power. For example, if 20 isolates are screened, the probability of identifying at least one with a cosmid conferring enhanced competitiveness is greater than $0.95(>0.95)$ if the enrichment is $10^{3}$ - to $10^{5}$-fold and the target is any size up to $24 \mathrm{~kb}$. 
Table 2. Evaluation of the role of cosmids in the enhanced competitiveness of strains derived from CE3

Each test strain was applied with CE3013 in approximately a 1:40 ratio (test strain: CE3013). The results are shown as the percentage of six nodules per plant occupied by the test strain alone $(\% \mathrm{~T})$ and by either CE3013 alone or both CE3013 and the test strain $(\% \mathrm{C}+\mathrm{B})$. Values are means from six plants. Values followed by the same letter do not differ significantly at $P=0.05$ when compared by a Fischer's LSD (least significant difference) on the arc sine square root transformation of the proportion of nodules occupied by the test strain.



* Strains isolated after two cycles of plant nodulation.

$\uparrow$ Strains constructed by introducing cosmids isolated from the above strains into the parent CE3.

$\ddagger$ Strains constructed by curing the cosmids from the strains listed in the first column.

$\S \mathrm{CE} 3$ ' was a stock culture of CE3.

\|These values are from a separate experiment.

Table 3. Competitiveness of $\mathrm{Cos}^{-} \mathrm{Cmp}^{++}$strains derived from strain CE3 relative to strain KIM5s

\begin{tabular}{lcccc}
\hline \hline & & \multicolumn{3}{c}{ Nodule occupancy $\dagger$} \\
\cline { 3 - 5 } Test strain & Inoculum ratio* & \% Test & \% KIM5s & \% Both $\ddagger$ \\
\hline CE3 & $12: 1$ & 17 & 69 & $14^{a}$ \\
CE3(c3) & $16: 1$ & 8 & 53 & $39^{a}$ \\
CE3(c1) & $11: 1$ & 76 & 7 & $17^{b c d}$ \\
CE3(c2) & $14: 1$ & 61 & 22 & $17^{b c}$ \\
CE3(c14) & $13: 1$ & 89 & 6 & $6^{c d}$ \\
CE3(c15) & $9: 1$ & 82 & 16 & $3^{b c}$ \\
CE3(c52) & $10: 1$ & 58 & 23 & $18^{b c}$ \\
CE3(c58) & $16: 1$ & 42 & 27 & $32^{b c d}$ \\
CE3(c71) & $11: 1$ & 69 & 19 & $11^{b c d}$ \\
CE3(c73) & $9: 1$ & 100 & 0 & $0^{d}$ \\
CE3(c75) & $11: 1$ & 48 & 27 & $26^{b}$ \\
\hline \hline
\end{tabular}

* Ratio of test strain to KIM5s in the inoculum.

$\dagger$ Percentage of six nodules per plant occupied by the test strain alone (\% Test), by KIM5s alone (\% KIM5s), and by both the test strain and KIM5s (\% Both). Values are means from six plants.

$\ddagger$ Values followed by the same letter do not differ significantly at $P=0.05$ when compared by a Fischer's LSD on the arc sine square root transformation of the proportion of nodules occupied by the test strain.

It is $>0.95$ if the enrichment is 100 -fold and the target is less than $14 \mathrm{~kb}$, but it is only 0.52 if the enrichment is 10 -fold and the target is as small as $1 \mathrm{~kb}$.

\section{Evaluation of the selective power of the plant}

To explore the power of the plant to select highly competitive strains from a mixture of strains, we measured the extent of the enrichment for KIM5s relative to CE3 after two plant passages. Application of a 1:50 (KIM5s:CE3) inoculum mixture to five bean seeds resulted in a ratio of $30: 1$ in the nodule isolate mixture, demonstrating a 1500 -fold enrichment for KIM5s. After a second passage, this ratio was 1100:1, demonstrating an additional 37-fold enrichment for KIM5s, and an overall enrichment of $5.6 \times 10^{4}$. In two replicate enrichment series, each involving two plant passages, we observed a $10^{3}$ - to $10^{5}$-fold enrichment for KIM5s relative to CE3.

\section{Competitiveness of the selected nodule isolates}

The strategy for the enrichment for transconjugants with enhanced competitiveness is illustrated in Fig. 2. Transconjugants containing 4000 independent cosmids were subjected to in planta enrichments in groups of 48 cosmids. A total of 75 nodule isolates, designated CE3(pOWR1) to CE3(pOWR75), were screened individually for enhanced competitiveness. We used the strain CE3013 as the reference strain in these competitions, since CE3013 was indistinguishable from CE3 
Table 4. Competitiveness of nodule isolates selected after plant passage of strains $C E 3(p L A F R 3), C E 3(p L A 2917), C E 3^{\prime}(p O W R 75)$ and $C E 3$

\begin{tabular}{|c|c|c|c|c|c|}
\hline Test strain & Source* & Inoculum ratio $\dagger$ & $\% \mathrm{~T} \ddagger$ & $\% \mathrm{C}+\mathrm{B}$ & $P \S$ \\
\hline CE3(pLAFR3) & $\begin{array}{c}\text { Control } \\
\text { N1 } \\
\text { N2 } \\
\text { N3 }\end{array}$ & $\begin{array}{l}1: 43 \\
1: 31 \\
1: 36 \\
1: 39\end{array}$ & $\begin{array}{l}6 \\
3 \\
3 \\
4\end{array}$ & $\begin{array}{l}94 \\
97 \\
97 \\
96\end{array}$ & 0.93 \\
\hline CE3(pLA2917) & $\begin{array}{c}\text { Control } \\
\text { N1 } \\
\text { N2 } \\
\text { N3 }\end{array}$ & $\begin{array}{l}1: 42 \\
1: 47 \\
1: 32 \\
1: 35\end{array}$ & $\begin{array}{r}0 \\
6 \\
11 \\
11\end{array}$ & $\begin{array}{r}100 \\
94 \\
89 \\
89\end{array}$ & 0.24 \\
\hline CE3'(pOWR75) & $\begin{array}{c}\text { Control } \\
\text { N1 } \\
\text { N2 } \\
\text { N3 }\end{array}$ & $\begin{array}{l}1: 45 \\
1: 48 \\
1: 36 \\
1: 44\end{array}$ & $\begin{array}{r}4 \\
4 \\
6 \\
13\end{array}$ & $\begin{array}{l}96 \\
96 \\
94 \\
87\end{array}$ & 0.85 \\
\hline $\begin{array}{l}\text { CE3(pOWR75) } \\
\text { CE3 } \\
\text { CE3 - mock mating }\end{array}$ & $\begin{array}{c}\text { Control } \\
\text { Control } \\
\text { N1 } \\
\text { N2 } \\
\text { N3 }\end{array}$ & $\begin{array}{l}1: 53 \\
1: 24 \\
1: 28 \\
1: 20 \\
1: 23\end{array}$ & $\begin{array}{r}61 \\
0 \\
0 \\
0 \\
6\end{array}$ & $\begin{array}{r}39 \\
100 \\
100 \\
100 \\
94\end{array}$ & $\begin{array}{l}0.003 \| \\
0.47\end{array}$ \\
\hline
\end{tabular}

* Control, parent strain from stock culture; $\mathrm{N}$, strain isolated from a nodule selected after the parent strain was subjected to two plant passages.

$\dagger$ Ratio of test strain to CE3013 in the inoculum.

$\$$ Percentage of six nodules per plant occupied by the test strain alone $(\% \mathrm{~T})$ and by either CE3013 alone or both the test strain and CE3013 (\% C+B). Values are means from six plants.

$\S$ Obtained from an ANOVA (analysis of variance) on the arc sine square root transformation of the proportion of nodules occupied by the test strain. Separate ANOVAs were performed on each the CE3 (pLAFR3) control strain and the following three nodule isolates, the CE3 (pLA2917) control strain and the following three nodule isolates, the CE3'(pOWR75) control strain and the following three nodule isolates, and the CE3 control strain and the following three nodule isolates.

$\| P$ value from an ANOVA on the arc sine square root transformation of the proportion of nodules occupied by each CE3'(pOWR75), the following three nodules isolates, and CE3(pOWR75).

in competitiveness (data not shown), but could be differentiated from $\mathrm{CE} 3$ or the cosmid-containing derivatives by antibiotic resistance.

After three rounds of enrichment, we identified nine nodule isolates that were more competitive than CE3 in competitions with CE3013. Six contained pLA2917derived cosmids; three contained pLAFR3-derived cosmids. In competitions between each of the nine test strains and a 40-fold excess of CE3013, the test strains typically occupied $15-40 \%$ of the nodules. When outnumbered 100 -fold by CE3013 in the inocula, these strains occupied $4-23 \%$ of the nodules. In contrast, when CE3 was outnumbered 40 - or 100 -fold by CE3013, it typically occupied only $0-3 \%$ of the nodules. We designated the phenotype of the nine strains that had enhanced competitiveness as $\operatorname{Cos}^{+} \mathrm{Cmp}^{++}$(Table 1).

\section{Role of the cosmids in enhanced competitiveness}

To evaluate similarities in the cosmids of the nine $\mathrm{Cos}^{+} \mathrm{Cmp}^{++}$strains, the EcoRI DNA restriction digest patterns of the cosmids from the strains were compared. Other than the fragment containing vector DNA, no fragment was common to all or even most of the cosmids, and no two cosmids shared more than four fragments of the same size. This demonstrates that the nine cosmids were distinct from each other.

We isolated the cosmids from the $\operatorname{Cos}^{+} \mathrm{Cmp}^{++}$strains and reintroduced them into a stock culture of CE3 to determine whether the cosmids conferred a competitive advantage on the recipients. We also cured the cosmids from the nine original $\operatorname{Cos}^{+} \mathrm{Cmp}^{++}$nodule isolates. Competitions were performed with each of these constructed strains and CE3013 at inoculum ratios of approximately 1:40 (Test strain:CE3013). Curing the $\mathrm{Cos}^{+} \mathrm{Cmp}^{++}$strains of their cosmids produced strains that remained highly competitive (Table 2). Furthermore, reintroducing the cosmids into CE3 did not enhance its competitiveness, since there were no significant differences in nodule occupancy by the test strain among the control strains CE3, CE3(pOWR3), CE3(c3), and all of the strains containing a reintroduced cosmid (Table 2). Together, these results indicate that the enhanced competitiveness of the nine $\mathrm{Cos}^{+} \mathrm{Cmp}^{++}$strains was not associated with the cosmids.

In three independent measurements, when outnumbered in the inocula approximately 40 -fold by CE3013, the nine $\mathrm{Cos}^{-}$strains derived from the $\mathrm{Cos}^{+} \mathrm{Cmp}^{++}$strains occupied between $31-50 \%$ of the nodules. In contrast, at similar inoculum ratios, CE3 
Table 5. Competitiveness of nodule isolates selected after plant passage of cultures of strain CE3

\begin{tabular}{|c|c|c|c|c|}
\hline \multirow{3}{*}{$\begin{array}{c}\text { Test } \\
\text { strain* }\end{array}$} & \multicolumn{4}{|c|}{ Ratio of test strain to CE3013 in the inoculum } \\
\hline & \multicolumn{2}{|c|}{$1: 10-1: 20$} & \multicolumn{2}{|c|}{$1: 23-1: 35$} \\
\hline & $\% \mathrm{~T} \dagger$ & $\% \mathrm{C}+\mathrm{B} \ddagger$ & $\% \mathrm{~T} \dagger$ & $\% \mathrm{C}+\mathrm{B} \ddagger$ \\
\hline CE3 & 3 & $97^{a b}$ & 9 & $91^{a b c}$ \\
\hline CE3 & 6 & $94^{a b c}$ & 3 & $97^{a b}$ \\
\hline N1 & 0 & $100^{a}$ & 0 & $100^{a}$ \\
\hline N2 & 3 & $97^{a b}$ & 4 & $96^{a b c}$ \\
\hline N3 & 4 & $96^{a b c}$ & 6 & $94^{a b c}$ \\
\hline N4 & 6 & $94^{a b c}$ & 0 & $100^{a}$ \\
\hline N5 & 6 & $94^{a b c}$ & 4 & $96^{a b c}$ \\
\hline N6 & 6 & $94^{a b c}$ & 10 & $90^{a b c}$ \\
\hline N7 & 8 & $92^{a b c}$ & - & - \\
\hline N8 & 15 & $85^{a b c d}$ & 0 & $100^{a}$ \\
\hline N9 & 19 & $81^{d}$ & 0 & $100^{a}$ \\
\hline N10 & 20 & $80^{d}$ & 6 & $94^{a b c}$ \\
\hline N11 & 33 & $67^{d}$ & 14 & $86^{c}$ \\
\hline
\end{tabular}

* CE3 was from a stock culture; $\mathrm{N}$, strain isolated from a nodule selected after a culture of CE3 was subjected to two plant passages.

† Percentage of six nodules per plant occupied by the test strain alone (\%T) and by either CE3013 alone or both the test strain and CE3013 $(\% \mathrm{C}+\mathrm{B})$. Values are means from six plants.

$\ddagger$ Values followed by the same letter do not differ significantly at $P=0.05$ when compared by a Fischer's LSD on the arc sine square root transformation of the proportion of nodules occupied by the test strain.

typically occupied $0-3 \%$ of the nodules. These $\mathrm{Cos}^{-} \mathrm{Cmp}^{++}$strains also occupied significantly more nodules than did CE3 or CE3(c3) in competitions with KIM5s (Table 3).

\section{Molecular characterization of the $\mathrm{Cos}^{-} \mathrm{Cmp}^{++}$strains}

Several genetic events could have resulted in the enhanced competitiveness of the $\mathrm{Cos}^{-} \mathrm{Cmp}^{++}$strains. To determine whether part or all of each cosmid had integrated into the genome of the $\mathrm{Cos}^{-}$strains, cosmids from the $\mathrm{Cos}^{+} \mathrm{Cmp}^{++}$strains were used to probe EcoRIdigested genomic DNA from $\mathrm{CE} 3$ and the $\mathrm{Cos}^{-} \mathrm{Cmp}^{++}$ strains. In every case, the probe hybridized with fragments of the same size and intensity in CE3 and in the cured strains (data not shown and Beattie, 1991).

To test whether the enhanced competitiveness of the $\mathrm{Cos}^{-} \mathrm{Cmp}^{++}$strains resulted from cosmid-induced genetic changes, we subjected three replicate cultures each of CE3'(pOWR75), CE3(pLAFR3), and CE3(pLA2917) to two plant passages and measured the competitiveness of selected nodule isolates. We chose CE3'(pOWR75) to test whether pOWR75, which did not affect competitiveness when simply reintroduced into CE3 (Table 2), could induce a change in competitiveness during plant passage. We found that none of the isolates selected after two plant passages occupied significantly more nodules in competition with CE3013 than did the respective parent strains (Table 4). If cosmid-induced changes in competitiveness occurred at a frequency of $10^{-2}$ or greater, then the probability of finding at least one $\mathrm{Cmp}^{++}$isolate out of three was $>0.95$, assuming an enrichment power of $\geqslant 10^{3}$. Similarly, if cosmid-induced changes occurred at frequencies of $10^{-3}$ or $10^{-4}$, then $P>0.88$ or $P>0.25$, respectively. Although we may not have examined enough cosmids to detect low frequency cosmid-induced changes $\left(\leqslant 10^{-3}\right)$, such low frequency changes were unlikely to be responsible for the enhanced competitiveness of the original $\mathrm{Cmp}^{++}$isolates. Assuming an enrichment power of $\geqslant 10^{3}$, the probability of identifying at least one $\mathrm{Cmp}^{++}$isolate among the original 75 isolates would be reduced from greater than 0.1 to well below 0.07 if the frequency at which $\mathrm{Cmp}^{++}$isolates arose were reduced from $10^{-2}$ to $10^{-3}$.

To test whether the enhanced competitiveness of the $\mathrm{Cos}^{-} \mathrm{Cmp}^{++}$strains resulted from cosmid-independent spontaneous changes that were induced and/or enriched for by plant passage, we subjected 11 replicate cultures of CE3 to two cycles of plant passage and measured the competitiveness of selected nodule isolates. Three isolates, N9, N10, and N11, appeared to be moderately enhanced in competitiveness (Table 5). All three occupied significantly more nodules than did CE3 at the lower inoculum ratio, i.e. 10- to 20-fold excess of CE3013 $(P<0.05)$. Although none of the three strains were enhanced in competitiveness to the same extent as the $\mathrm{Cos}^{-} \mathrm{Cmp}^{++}$strains, these data show that genetic variants with a moderate increase in competitiveness arose spontaneously. To test for a role of the conjugation procedure in inducing or enriching for genetic changes that cause increased competitiveness, we subjected three replicate cultures of CE3 to a mock-mating protocol and to two cycles of plant passage. None of the selected isolates were $\mathrm{Cmp}^{++}$(Table 4).

\section{Physiological characterization of the $\mathrm{Cos}^{-} \mathrm{Cmp}^{++}$strains}

$\mathrm{CE} 3, \mathrm{CE} 3(\mathrm{c} 3)$, and all nine $\mathrm{Cos}^{-} \mathrm{Cmp}^{++}$strains grew in a rich medium in batch culture with doubling times between 2.29 and $2.40 \mathrm{~h}$. There were no significant differences among the strains in growth rate or in the number of bacteria required to induce nodules. Additionally, acetylene reduction assays showed that CE3, $\mathrm{CE} 3(\mathrm{c} 3)$, and the nine $\mathrm{Cos}^{-} \mathrm{Cmp}^{++}$strains were all capable of fixing nitrogen (Beattie, 1991).

\section{Discussion}

To identify nodulation competitiveness genes in $R$. leguminosarum bv. phaseoli, we attempted to transfer genes that confer enhanced competitiveness from a superior competitor, strain KIM5s, to an inferior 
competitor, strain CE3. We identified nine highly competitive derivatives. Surprisingly, we found that the enhanced competitiveness of these nine strains did not appear to be due to the introduced DNA.

We found no evidence of cosmid insertion or of genetic changes induced by the cosmids in the $\operatorname{Cos}^{-} \mathrm{Cmp}^{++}$strains (i.e. the strains that were cured of the cosmids but remained highly competitive). Our studies were limited by the fact that all of the cosmids used in these studies were isolated after the original transconjugants were subjected to the enrichments. Therefore, we cannot eliminate the possibility that these cosmids were altered during the course of the enrichments by a process such as loss of a region by homologous recombination or transposition.

The most plausible explanation for the altered competitiveness of the $\mathrm{Cos}^{-} \mathrm{Cmp}^{++}$strains is that it resulted from spontaneous genetic changes. In experiments designed to reconstruct the events that produced the nine highly competitive strains, we identified several isolates that arose spontaneously and were more competitive than CE3, although none were as competitive as the original nine $\mathrm{Cos}^{-} \mathrm{Cmp}^{++}$strains. That none were highly competitive could be due to the absence of conditions necessary to induce such mutations or to chance, since the probability of identifying at least one $\mathrm{Cmp}^{++}$isolate among the 11 from the CE3 enrichments was only 0.75 , based on finding $\mathrm{Cmp}^{++}$isolates at a frequency of $12 \%$ among the original 75 isolates. To identify at least one $\mathrm{Cmp}^{++}$isolate when such isolates arose at a frequency of $12 \%$, with $P>0.95$, we would need to screen at least 24 isolates.

Spontaneous changes that might have caused the $\mathrm{Cmp}^{++}$phenotype include point mutations, insertion of mobile elements, and genomic rearrangements. Although insertion sequences that transpose at frequencies of $10^{-2}$ to $10^{-3}$ have been reported in several Rhizobium spp. (Dusha et al., 1987; Priefer et al., 1980; Ruvkun et al., 1982), none have been reported in $R$. leguminosarum bv. phaseoli. Genomic rearrangements have been shown to occur at frequencies as high as $10^{-2}$ in the parent strain of CE3, CFN42 (Brom et al., 1991; Romero et al., 1991). We examined the $\operatorname{Cos}^{-} \mathrm{Cmp}^{++}$strains but did not find evidence of rearrangements with endpoints in the nifH gene (Beattie, 1991), which are known to occur at a high frequency in CFN42 (Romero et al., 1991).

Genetic alterations that result in increased competitiveness have been observed previously. Studies have correlated the presence of a plasmid (Bromfield et al., 1985; Hynes, 1990; Martínez-Romero \& Rosenblueth, 1990; Sanjuan \& Olivares, $1991 b$ ) and the presence of multiple copies of a gene (Sanjuan \& Olivares, 1991 a) to increased competitiveness. Others have correlated the inactivation of genes involved in EPS production (Zdor
\& Pueppke, 1991) and succinate sensitivity (Urban, 1988) with increased competitiveness. Recently, Bhagwat \& Keister (1992) used an elegant subtractive hybridization strategy to clone a gene that affects competitiveness of $B$. japonicum. In addition to the many genetic changes reported to increase competitiveness, our study suggests that genetic changes that increase competitiveness may occur spontaneously.

We may not have identified nodulation competitiveness genes in KIM5s for several reasons. First, genes that confer enhanced competitiveness simply may not exist in KIM5s. Perhaps the competitiveness of KIM5s is due to the lack of certain factors present in CE3. Second, if such genes do exist, they may be scattered throughout the KIM5s genome, or they may not be functionally dominant in CE3. And third, if such genes were successfully transferred to CE3, they may have been expressed only at a low level or they may have resulted in only a moderate increase in competitiveness. We may not have identified them in this study because the increases in competitiveness that they caused were much smaller than the increases we observed, and therefore we did not choose the appropriate transconjugants for further study. If KIM5s contained a region of DNA that could be transferred to CE3 and conferred competitiveness equal to that of KIM5s, the probability that we would have identified it among the 75 isolates screened was $>0.99$. Therefore, assuming that our library was random and fairly complete, such a region probably does not exist in KIM5s.

The $10^{3}$ - to $10^{5}$-fold enrichment for KIM5s from a mixture of KIM5s and CE3 demonstrates that the host plant can be a very powerful tool for enriching for highly competitive strains. Theoretically, the success of the direct cloning and enrichment approach depends on the extent to which the target DNA enhances the competitiveness of the recipient strain. As shown in Fig. 1, even a $10^{3}$-fold enrichment should result in at least $50 \%$ of the isolates containing the target DNA, if the required target DNA region were as large as $18 \mathrm{~kb}$. This corresponds to a probability of greater than 0.99 that at least one isolate would contain the target region if 75 isolates are screened. However, as we found, other factors can influence the results. It should be possible to directly isolate cosmids containing genes that can confer enhanced competitiveness, such as $t f x$ (Triplett, 1990), nfe (Sanjuan \& Olivares, 1991 b), and nif A (Sanjuan \& Olivares, 1991a). Therefore, the lack of success of the approach with KIM5s and CE3 does not reflect on its potential for success with other strains.

In summary, in an attempt to transfer genes that confer enhanced nodulation competitiveness from a superior competitor of $R$. leguminosarum bv. phaseoli to an inferior competitor, we isolated several highly 
competitive variants, whose altered competitiveness was not associated with the introduced DNA. Since they were very similar to their parent, any physiological differences between the variants and their parent are likely to be associated with, and may be causal to, their enhanced competitiveness. These variants, therefore, may provide insight into bacterial traits that affect successful nodulation competitiveness.

We thank G. Roberts, F. Bliss, and F. Ausubel for helpful discussion in the early phases of this work. We also thank E. Triplett, L. Sequeira, and $\mathrm{S}$. Lindow for comments on the manuscript.

This work was supported by USDA Grant No. 89-37262-4746 and the University of Wisconsin College of Agricultural and Life Sciences Project No. 3309. G.A.B. was supported by Public Health Service grant GM07215 from the National Institutes of Health.

\section{References}

Allen, L. N. \& Hanson, R. S. (1985). Construction of broad-hostrange cosmid cloning vectors: identification of genes necessary for growth of Methylobacterium organophilum on methanol. Journal of Bacteriology 161, 955-962.

AMARGER, N. (1981). Competition for nodule formation between effective and ineffective strains of Rhizobium meliloti. Soil Biology and Biochemistry 13, 475-480.

AMES, P. \& BERGMAN, K. (1981). Competitive advantage provided by bacterial motility in the formation of nodules by Rhizobium meliloti. Journal of Bacteriology 148, 728-729.

Anderson, A. J., Habibzadegah-TARI, P. \& TePPER, C. S. (1988). Molecular studies on the role of a root surface agglutinin in adherence and colonization by Pseudomonas putida. Applied and Environmental Microbiology 54, 375-380.

ARAujo, R. S. \& Handelsman, J. (1990). Characteristics of exopolysaccharide-deficient mutants of Rhizobium spp. with altered nodulation competitiveness. In Nitrogen Fixation: Achievements and objectives, p. 247. Edited by P. M. Gresshoff, L. E. Roth, G. Stacey, and W. E. Newton. New York: Chapman and Hall.

araujo, R. S., Maya-Flores, J., Barnes-McConnell, D., Yokoyama, C., Dazzo, F. B. \& Bliss, F. A. (1986). Semienclosed tube cultures of bean plants (Phaseolus vulgaris $\mathbf{L}$.) for enumeration of Rhizobium phaseoli by the most-probable-number technique. Applied and Environmental Microbiology 52, 954-956.

Ausubel, F. M., Brent, R., Kingston, R. E., Moore, D. D., Seidman, J. G., SMith, J. A. \& Struhl, K. (eds). (1987). Current Protocols in Molecular Biology. New York: John Wiley \& Sons.

BEATTIE, G. A. (1991). Quantitative and molecular analysis of nodulation competitiveness in Rhizobium leguminosarum biovar phaseoli. $\mathrm{PhD}$ thesis, University of Wisconsin-Madison.

Beattie, G. A. \& Handelsman, J. (1989). A rapid method for the isolation and identification of Rhizobium from root nodules. Journal of Microbiological Methods 9, 29-33.

Beattie, G. A., Clayton, M. K. \& Handelsman, J. (1989). Quantitative comparison of the laboratory and field competitiveness of Rhizobium leguminosarum biovar phaseoli. Applied and Environmental Microbiology 55, 2755-2761.

BERGERSEN, F. J. (1961). The growth of Rhizobium in synthetic media. Australian Journal of Biological Science 14, 349-360.

Bhagwat, A. A. \& Keister, D. L. (1990). Competition defective mutants of Bradyrhizobium japonicum. In Nitrogen Fixation: Achievements and Objectives, p. 251. Edited by P. M. Gresshoff, L. E. Roth, G. Stacey, and W. E. Newton. New York: Chapman and Hall.

BhaGWAT, A. A. \& KeISTER, D. L. (1992). Identification and cloning of Bradyrhizobium japonicum genes expressed strain selectively in soil and rhizosphere. Applied and Environmental Microbiology 58, 1490-1495.

BIRNBOIM, H. C. (1983). A rapid alkaline extraction method for the isolation of plasmid DNA. Methods in Enzymology 100, 243-255.
Brom, S., García de los Santos, A., Girard, M. L., Dávila, G., PALACIOS, R. \& RoMERO, D. (1991). High-frequency rearrangements in Rhizobium leguminosarum bv. phaseoli plasmids. Journal of Bacteriology 173, 1344-1346.

Bromfield E. S. P., Lewis, D. M. \& Barran, L. R. (1985). Cryptic plasmid and rifampicin resistance in Rhizobium meliloti influencing nodulation competitiveness. Journal of Bacteriology 164, 410-413.

Caetano-Anollés, G., Wall, L. G., de Micheli, A. T., Macchi, E. M., Bauer, W. D. \& Favelukes, G. (1988). Role of motility and chemotaxis in efficiency of nodulation by Rhizobium meliloti. Plant Physiology 86, 1228-1235.

Clarke, L. \& Carbon, J. (1976). A colony bank containing synthetic Col E1 hybrid plasmids representative of the entire E. coli genome. Cell 9, 91-99.

Douglas, C. J., Staneloni, R. J., Rubin, R. A. \& Nester, E. W. (1985). Identification and genetic analysis of an Agrobacterium tumefaciens chromosomal virulence region. Journal of Bacteriology 161, 850-860.

Dusha, I., Kovalenko, S., Banfalvi, Z. \& Kondorosi, A. (1987). Rhizobium meliloti insertion element ISRm2 and its use for identification of the fixX gene. Journal of Bacteriology 169, 1403-1409.

FigURSKI, D. H. \& Helinski, D. R. (1979). Replication of an origincontaining derivative of plasmid RK2 dependent on a plasmid function provided in trans. Proceedings of the National Academy of Sciences of the United States of America 76, 1648-1652.

Gray, J. X., DJordJEVIC, M. A. \& Rolfe, B. G. (1990). Two genes that regulate exopolysaccharide production in Rhizobium sp. strain NGR234: DNA sequences and resultant phenotypes. Journal of Bacteriology 172, 193-203.

Grimm, C. \& Panopoulos, N. J. (1989). The predicted protein product of a pathogenicity locus from Pseudomonas syringae pv. phaseolicola is homologous to a highly conserved domain of several procaryotic regulatory proteins. Journal of Bacteriology 171, 5031-5038.

HAEFELE, D. M. \& LinDOW, S. E. (1987). Flagellar motility confers epiphytic fitness advantages upon Pseudomonas syringae. Applied and Environmental Microbiology 53, 2528-2533.

HAHN, M. \& HENNECKE, H. (1988). Cloning and mapping of a novel nodulation region from Bradyrhizobium japonicum by genetic complementation of a deletion mutant. Applied and Environmental Microbiology 54, 55-61.

HAHN, M. \& STUDER, D. (1986). Competitiveness of a nif Bradyrhizobium japonicum mutant against the wild-type strain. FEMS Microbiology Letters 33, 143-148.

Handelsman, J., Ugalde, R. A. \& Brill, W. J. (1984). Rhizobium meliloti competitiveness and the alfalfa agglutinin. Journal of Bacteriology 157, 703-707.

haugland, R. A., Cantrell, M. A., Beaty, J. S., Hanus, F. J., Russell, S. A. \& Evans, H. J. (1984). Characterization of Rhizobium japonicum hydrogen uptake genes. Journal of Bacteriology 159, 1006-1012.

Holmes, D. S. \& Quigley, M. (1981). A rapid boiling method for the preparation of bacterial plasmids. Analytical Biochemistry 114, 193-197.

HYNES, M. F. (1990). The role of plasmids in competition between strains of Rhizobium leguminosarum. In Nitrogen Fixation: Achievements and Objectives, p. 262. Edited by P. M. Gresshoff, L. E. Roth, G. Stacey, and W. E. Newton. New York: Chapman and Hall.

KaHN, M. L. \& Timblin, C. R. (1984). Gene fusion vehicles for the analysis of gene expression in Rhizobium meliloti. Journal of Bacteriology 158, 1070-1077.

Kondorosi, A. (1989). Rhizobium-legume interaction: nodulation genes. In Plant-Microbe Interactions. Molecular and Genetic Perspectives, vol. 3, pp. 383-420. Edited by T. Kosuge \& E. W. Nester. New York: McGraw-Hill.

lagares, A, Caetano-Anollés, G., Niehaus, K., Lorenzen, J., LjUngGren, H. D., PÜHLER \& Favelukes, G. (1992). A Rhizobium meliloti lipopolysaccharide mutant altered in competitiveness for nodulation of alfalfa. Journal of Bacteriology 174, 5941-5952.

Lambert, G. R., Harker, A. R., Cantrell, M. A., Hanus, F. J., Russell, S. A., Haugland, R. A. \& Evans, H. J. (1987). Symbiotic 
expression of cosmid-borne Bradyrhizobium japonicum hydrogenase genes. Applied and Environmental Microbiology 53, 422-428.

Lindgren, P. B., Peet, R. C. \& Panopoulos, N. J. (1986). Gene cluster of Pseudomonas syringae pv. 'phaseolicola' controls pathogenicity of bean plants and hypersensitivity on nonhost plants. Journal of Bacteriology 168, 512-522.

LiU, R., Tran, V. M. \& Schmidt, E. L. (1989). Nodulating competitiveness of a nonmotile Tn7 mutant of Bradyrhizobium japonicum in nonsterile soil. Applied and Environmental Microbiology 55, 1895-1900.

Long, S. R., Buikema, W. J. \& Ausubel, F. M. (1982). Cloning of Rhizobium meliloti nodulation genes by direct complementation of Nod $^{-}$mutants. Nature, London 298, 485-488.

MÁrtinez-Romero, E. \& Rosenblueth, M. (1990). Increased bean (Phaseolus vulgaris L.) nodulation competitiveness of genetically modified Rhizobium strains. Applied and Environmental Microbiology 56, 2384-2388.

Mcloughlin, T. J., Merlo, A. O., Satola, S. W. \& Johansen, E. (1987). Isolation of competition-defective mutants of Rhizobium fredii. Journal of Bacteriology 169, 410-413.

Mellor, H. Y., GlenN, A. R., ARWAS, R. \& Dilworth, M. J. (1987). Symbiotic and competitive properties of motility mutants of Rhizobium trifolii TA1. Archives of Microbiology 148, 34-39.

Milner, J. L., Araujo, R. S. \& Handelsman, J. (1992). Molecular and symbiotic characterization of exopolysaccharide-deficient mutants of Rhizobium tropici strain CIAT899. Molecular Microbiology 6, 3137-3147.

Noel, K. D., Sanchez, A., Fernandez, L., Leemans, J. \& Cevallos, M. A. (1984). Rhizobium phaseoli symbiotic mutants with transposon Tn 5 insertions. Journal of Bacteriology 158, 148-155.

O'Connell, K. P. \& Handelsman, J. (1989). chva locus may be involved in export of neutral cyclic $\beta$-1,2-linked D-glucan from Agrobacterium tumefaciens. Molecular Plant-Microbe Interactions 2 , 11-16.

Priefer, U. B., Burkardt, H. J., Klipp, W. \& PüHler, A. (1980). ISR 1: an insertion element isolated from the soil bacterium Rhizobium lupini. Cold Spring Harbor Symposium on Quantitative Biology 45, 87-91.

Romero, D., Brom, S., Mártinez-Salazar, J., Girard, M. L., Palacios, R. \& DÁvila, G. (1991). Amplification and deletion of a nod-nif region in the symbiotic plasmid of Rhizobium phaseoli. Journal of Bacteriology 173, 2435-2441.

Ronald, P. C. \& STASKaWICZ, B. J. (1988). The avirulence gene $a v r B s_{1}$ from Xanthomonas campestris pv. vesicatoria encodes a $50-\mathrm{kD}$ protein. Molecular Plant-Microbe Interactions 1, 191-198.

Ruvkun, G. B., Long, S. R., Meade, H. M., Van Den Bos, R. C. \& Ausubel, F. M. (1982). ISRm1: a Rhizobium meliloti insertion sequence that transposes preferentially into nitrogen fixation genes. Journal of Molecular and Applied Genetics 1, 405-418.

RynNe, F., Dilworth, M. J. \& GlenN, A. R. (1988). Effect of aromatic metabolism on the competitiveness and persistence of
Rhizobium trifolii WU95. In Nitrogen Fixation: Hundred Years After, p. 787. Edited by H. Bothe, F. J. de Bruijn \& N. E. Newton. New York: Gustav Fischer Verlag.

SANJUAN, J. \& Olivares, J. (1991 $a$ ). Multicopy plasmids carrying the Klebsiella pneumoniae nifA gene enhance Rhizobium meliloti nodulation competitiveness on alfalfa. Molecular Plant-Microbe Interactions 4, 365-369.

Sanjuan, J. \& Olivares, J. (1991 $b$ ). NifA-NtrA regulatory system activates transcription of $n f e$, a gene locus involved in nodulation competitiveness of Rhizobium meliloti. Archives of Microbiology 155 , 543-548.

Sobral, B. W. S., Honeycutt, R. J., Atherly, A. G. \& McClelland, M. (1991). Electrophoretic separation of the three Rhizobium meliloti replicons. Journal of Bacteriology 173, 5173-5180.

Somasegaran, P. \& HoBen, H. (1985). Methods in Legume-Rhizobium Technology. University of Hawaii NifTAL Project, Paia, Hawaii, pp. 320-327.

Staskawicz, B., Dahlbeck, D., Keen, N. \& Napoli, C. (1987). Molecular characterization of cloned avirulence genes from race 0 and race 1 of Pseudomonas syringae pv. glycinea. Journal of Bacteriology 169, 5789-5794.

Swanson, J., Kearney, B., Dahlbeck, D. \& Staskawicz, B. (1988). Cloned avirulence gene of Xanthomonas campestris pv. vesicatoria complements spontaneous race-change mutants. Molecular PlantMicrobe Interactions 1, 5-9.

Trinick, M. J. \& Hadobas, P. A. (1989). Competition by Bradyrhizobium strains for nodulation of the nonlegume Parasponia andersonii. Applied and Environmental Microbiology 55, 1242-1248.

TRIPLETT, E. W. (1988). Isolation of genes involved in nodulation competitiveness from Rhizobium leguminosarum bv. trifolii T24. Proceedings of the National Academy of Sciences of the United States of America 85, 3810-3814.

TRIPLETT, E. W. (1990). Construction of a symbiotically effective strain of Rhizobium leguminosarum bv. trifolii with increased competitiveness. Applied and Environmental Microbiology 56, 98-103.

TripletT, E. W. \& Barta, T. M. (1987). Trifolitoxin production and nodulation are necessary for the expression of superior nodulation competitiveness of Rhizobium leguminosarum bv. trifolii strain T24 on clover. Plant Physiology 85, 335-342.

Ugalde, R. A., Handelsman, J. \& Brill, W. J. (1986). Role of galactosyltransferase activity in phage sensitivity and nodulation competitiveness of Rhizobium meliloti. Journal of Bacteriology 166, $148-154$.

URBAN, J. (1988). Use of succinate-sensitive inoculants increases nodule number and seed yields in legumes. In Nitrogen Fixation: Hundred Years After, p. 566. Edited by H. Bothe, F. J. de Bruijn \& W. E. Newton. New York: Gustav Fischer.

WACEK, T. J. \& BRILL, W. J. (1976). Simple, rapid assay for screening nitrogen-fixing ability in soybean. Crop Science 16, 519-523.

ZDOR, R. E. \& PUEPPKE, S. G. (1991). Nodulation competitiveness of Tn5-induced mutants of Rhizobium fredii USDA208 that are altered in motility and extracellular polysaccharide production. Canadian Journal of Microbiology 37, 52-58. 